\title{
Temporary remission of advanced hepatocellular carcinoma in a patient treated with sorafenib therapy alone - A case report and literature review
}

\author{
Simran Elder ${ }^{1}$ and Yixing Jiang ${ }^{2 *}$ \\ ${ }^{1}$ University of Maryland School of Medicine, Baltimore, USA \\ ${ }^{2}$ Marlene and Stewart Greenebaum Cancer Center, University of Maryland Medical Center, Baltimore, USA
}

\begin{abstract}
Hepatocellular carcinoma (HCC) is a primary liver tumor which has been increasing in incidence over the past several years [1], and is the second leading cause of cancer death in the world [2]. Advanced HCC usually carries a poor prognosis. Over the past decade, systemic therapy for HCC has been evolving rapidly offering more therapeutic options and longer survival for those with incurable HCC. Here, we report a case of advanced HCC treated with single agent sorafenib and achieved complete radiographic response. In this article, we also provide a summary of current status of systemic therapy for HCC.
\end{abstract}

\section{Case}

A 57-year-old Asian male with a longstanding history of hepatitis $\mathrm{C}$ treated two years prior with Interferon as well as past history of heavy alcohol use and current smoking was evaluated by his primary care physician for right upper quadrant abdominal pain radiating to his back for four weeks. He was found on Computed Tomography (CT) scan to have a large mass in the right lobe of the liver suspicious for hepatocellular carcinoma, in conjunction with an Alpha-fetoprotein (AFP) of $78 \mathrm{IU} / \mathrm{mL}$ (previous value was reportedly $38 \mathrm{IU} / \mathrm{mL}$ ). Unfortunately, the patient was then lost to follow up for 15 months due to social stressors. Upon return to care, further CT imaging showed multifocal hypervascular lesions involving both lobes of the liver, the largest being $11.5 \times 7.5 \times 15.7 \mathrm{~cm}$ with associated portal vein thrombosis, portal lymphadenopathy, and narrowing of the infrahepatic IVC (Figure 1). Biopsy of the largest lesion showed hepatocellular carcinoma in a background of cirrhosis.

Physical exam revealed normal vital signs, anicteric sclerae and no jaundice. He was noted to have a palpable liver $5 \mathrm{~cm}$ below the costal margin, and he did not have appreciable ascites. He was noted to have several tattoos, and otherwise had an unremarkable physical exam. The mass was deemed to be unresectable and not amenable to cure by transplant, thus the options of chemotherapy, chemoembolization

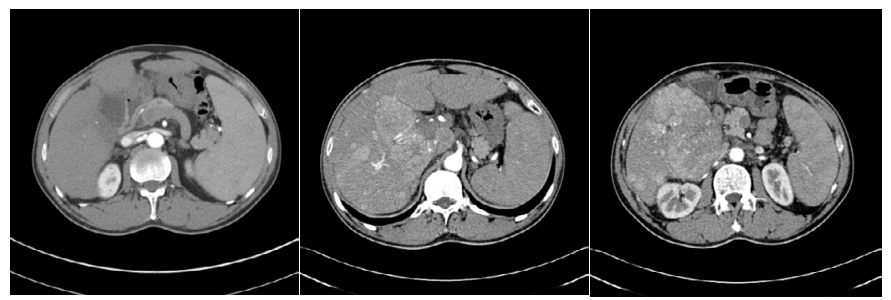

Figure 1 (a-c). CT performed 15 months after initial visit, before Sorafenib initiation, demonstrating involvement of both lobes of liver. The largest lesion is $11.5 \times 7.5 \times 15.7 \mathrm{~cm}$ with associated portal vein thrombosis, portal lymphadenopathy, and narrowing of the infrahepatic IVC and possible clinical trial participation were discussed with the patient. He was then referred to a Gastrointestinal Oncology specialist. It was determined that chemoembolization would not be ideal in the context of the patient's portal vein occlusion, and that unfortunately he was not a candidate for any available clinical trials at the time. His AFP was noted to rise to $387 \mathrm{IU} / \mathrm{mL}$ (Figure 2), with platelets of $104,000 / \mathrm{mL}$, ALT 305 units/L, AST 579 units/L, alkaline phosphatase 426 units/L total bilirubin $1 \mathrm{mg} / \mathrm{dL}$, WBC $2800 / \mathrm{mL}$ hemoglobin $12 \mathrm{mg} / \mathrm{dL}$, albumin 3.9 $\mathrm{g} / \mathrm{dL}$, creatinine $0.98 \mathrm{mg} / \mathrm{dL}$. The option of Sorafenib was presented to the patient, which he agreed to and was initiated on Sorafenib $400 \mathrm{mg}$ by mouth twice daily. One month later, the patient was noted to have a decrease in AFP $(19.6 \mathrm{IU} / \mathrm{mL})$ but developed hand foot syndrome as a result of Sorafenib. The Sorafenib was held briefly and restarted at 200 mg po TID. He tolerated this well, but 5 months later AFP was noted to have risen to $29.9 \mathrm{IU} / \mathrm{mL}$. His CT, however, showed miraculous response with almost complete resolution of the previously seen large hepatic mass with normalization of liver architecture (Figure 3). This response was sustained for 15 months, at which time he was then found to have a new liver lesion on CT scan (Figure 4) with an AFP of 10.4 $\mathrm{IU} / \mathrm{ml}$. He was referred to interventional radiology and underwent transarterial chemoembolization (TACE) of this lesion, with good response on follow up CT scan two months later with stable AFP at $12.2 \mathrm{IU} / \mathrm{mL}$, then $11.8 \mathrm{IU} / \mathrm{mL}$. Sorafenib $400 \mathrm{mg}$ by mouth daily was resumed. Two months later, he was noted to have a slightly increased AFP value at $28.6 \mathrm{IU} / \mathrm{mL}$, with CT scan notable for a new hypervascular lesion in segment V (Figure 4). Sorafenib was continued and he was

${ }^{*}$ Correspondence to: Yixing Jiang, Marlene and Stewart Greenebaum Cancer Center, University of Maryland Medical Center, Baltimore, USA, E-mail: yjiang@umm.edu

Key words: hepatocelluar carcinoma, sorafenib, remission

Received: February 21, 2019; Accepted: March 18, 2019; Published: March 22, 2019 


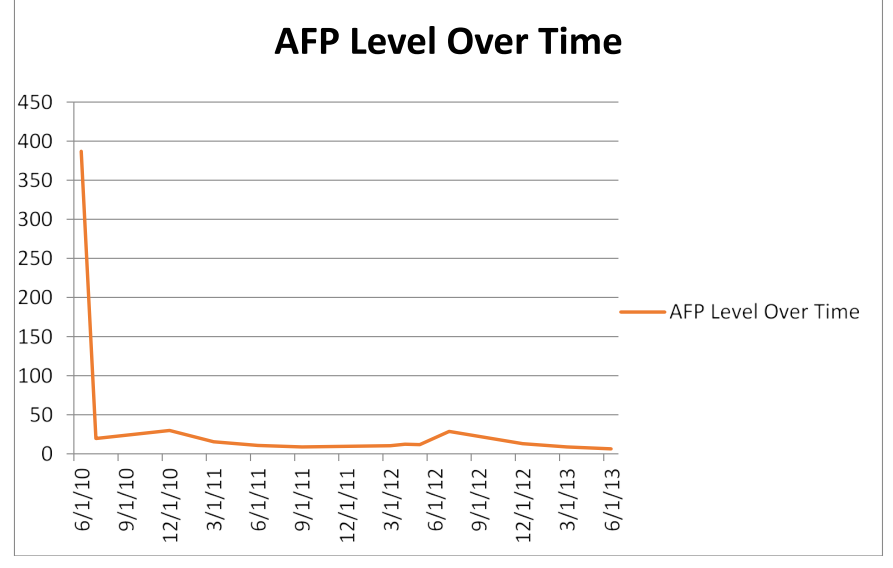

Figure 2. Reduction AFP level while on sorafenib

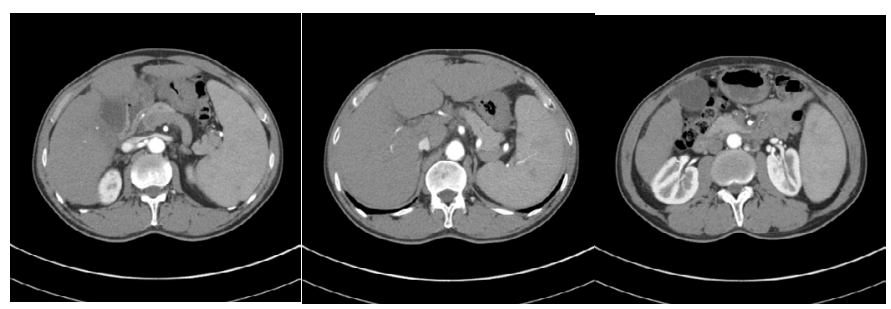

Figure 3 (a-c). CT scan repeated 6 months after Sorafenib initiation showing resolution of previously seen masses in liver and improvement in splenomegaly

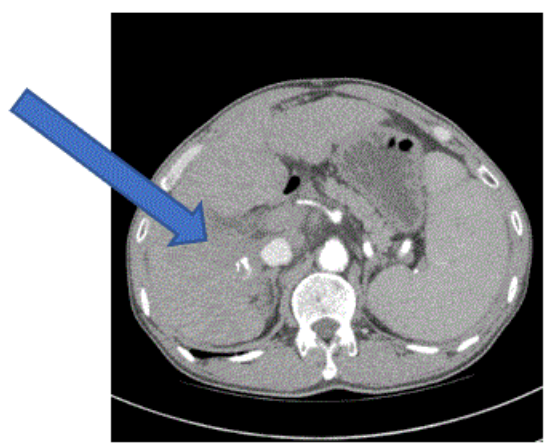

Figure 4. CT scan image 21 months after Sorafenib initiation demonstrating new hypervascular $18 \times 17 \mathrm{~mm}$ lesion in liver segment 5 (arrow)

offered the option of transplant, but declined this. He did have a slight decrease in size of the liver lesions on next two CT scans with AFP of $13,8.7$ and finally $6.3 \mathrm{IU} / \mathrm{mL}$.

\section{First line therapy for advanced hepatocellular carcinoma}

For many years, there was not a standard first line therapy for advanced HCC until 2008 when SHARP trial was published [3]. The SHARP trial was a phase III study to evaluate single agent sorafenib versus best supportive care in patients with advanced HCC. A total of 602 patients were randomized to receive sorafenib or placebo. The median overall survival (OS) in the sorafenib arm was 10.7 months while in the placebo arm it was 7.9 months. The moderate prolongation of survival time was statistically significant ( $95 \%$ confidence interval: $0.55-0.87 ; \mathrm{P}<0.001)$. The partial response rate in sorafenib group was $2 \%$. More than $70 \%$ patients experienced stable disease. The progression free survival was also superior in the sorafenib group (5.5 months vs 2.8 months). In 2009, Cheng et al published data of a phase III trial using sorafenib in Asian patients with advanced HCC [4]. The study accrued 271 patients with 150 assigned to sorafenib and 76 patients to placebo. The median OS was 6.5 months with sorafenib and 4.2 months with placebo (HR 0.68; 95\% CI $0.5-0.93 ; \mathrm{P}=0.14$ ). It is noted that majority patients in SHARP study were Hepatitis $\mathrm{C}$ or alcohol related liver cirrhosis while the more than $70 \%$ patients in the latter trial were Hepatitis B positive. These two large phase III studies set the standard of care of first line therapy for advanced HCC worldwide.

Since the approval of Sorafenib, three tyrosine kinase inhibitors have been evaluated against Sorafenib to treat HCC in the first line setting. In 2013, Brivanib and Sunitinib were assessed in two large phase III studies. Brivanib is a dual receptor kinase inhibitor of VEGR and FGFR. Phase II data showed that Brivanib achieved $11 \%$ objective response rate and $72 \%$ disease control rate in patients refractory to Sorafenib [5]. Brivanib as first line therapy demonstrated an OS of 9.8 months reported in a phase II study [6]. These encouraging results led to a randomized phase III trial comparing Brivanib to Sorafenib as first line therapy in advanced HCC, the BRISK study [7]. The results was rather disappointing. The median OS for Sorafenib was 9.9 months vs. 9.5 moths for Brivanib. The BRISK-PS study compared Brivanib to placebo in patients who failed Sorafenib. More disappointingly, Brivanib did not improve OS over placebo [8]. The efficacy of Sunitinib was assessed in a large phase III study for first line therapy in HCC as well. The study enrolled total of 1074 patients worldwide. The median OS was 7.9 months in Sunitinib arm and 10.2 months in Sorafenib arm [9]. Sunitinib is associated with more severe adverse events. Linifanib is a VEGFR and PDGFR inhibitor. Linifanib showed significant activity in HCC in a single arm phase II study where a median OS of 9.7 months was reached [10]. Once again, Linifanib failed to demonstrate superiority to Sorafenib in a randomized phase III trial [10].

To improve the efficacy of Sorafenib, the combination of Sorafenib with other small molecules has been tried. Zhu et al reported a phase III study comparing Sorafenib with either Erlotinib or placebo in the SEARCH trial. A total of 720 patients were randomized in the study. The combination therapy neither improved OS ( 9.5 months in the combination arm; 8.5 moths in the sorafenib arm) nor response rate (6.6\% for the combination; $3.9 \%$ for sorafenib) [11].

After many failures, Lenvatinib was tested for first line therapy in a randomized, non-inferiority phase III trial [12]. Lenvatinib is a multikinase inhibitor of VEGFR, FGFR, PDGFR, RET and KIT. It has a proven role in the treatment of advanced renal cell carcinoma. A total of 954 patients were randomized to either receive Lenvatinib or Sorafenib. Lenvatinib achieved a surprising high response rate of $24 \%$. However, the response rate $(9.2 \%)$ in the Sorafenib arm was a bit higher comparing to the historical data. Median OS for Lenvatinib was 13.6 months and 12.3 months for Sorafenib. The toxicity profile for Lenvatinib is very similar to Sorafenib except for increasing dysphonia, hypothyroidism and vomiting with Lenvatinib, but overall, the medication is tolerable. The study met its primary objective of non-inferiority to Sorafenib. Patients with disease occupying more than $50 \%$ of the liver, bile duct invasion or main portal vein invasion were excluded from the study. One could argue that this study population is slightly healthier than that of previous HCC trials in the literature. Nonetheless, this pivotal trial set the new standard for first line therapy of advanced HCC (Table $1)$.

\section{Immune checkpoint inhibitors}

The FDA granted accelerated approval for Nivolumab (9/2017) and Pembrolizumab (11/2018), both monoclonal antibodies to PD1 , for advanced HCC progressed on the first line therapy based on phase II data. CheckMate-040 is a phase I/2 dose escalation and 
expansion trial [13]. A total of 262 patients were treated with single agent Nivolumab. The study demonstrated $20 \%$ response rate at a dose of $3 \mathrm{mg} / \mathrm{kg}$. The overall survival time has not yet been reached. KEYNOTE-224 is a single arm phase II study in which a total of 104 eligible patients were treated with single agent Pembrolizumab [14]. Similar to Nivolumab, a response rate of $17 \%$ was achieved. The response was durable. A significant amount of patients were on therapy for more than 60 weeks. The high response rate and long duration of response are rarely observed with any other agents in HCC. Based on these promising data, FDA granted accelerated approval of both agents to be used as second line therapies pending phase III results. 2/19/19, Merck announced the results of KEYNOTE-240 phase III study. To everyone's surprise, Pembrolizumab failed to demonstrate a statistically significant survival benefit over best supportive care although there is a trend of OS and PFS benefit toward Pembrolizumab (OS:HR=0.78; 95\% CI 0.611-0.998; $\mathrm{P}=0.0238$. PFS: HR=0.78; 95\% CI 0.661-0.99; $\mathrm{P}=0.0209$ ). The phase III results of CheckMate- 040 are awaited.

While results from trials of single agent immune checkpoint inhibitors have been rather disappointing, combination therapy is being actively explored. One such promising combination is Atezolizumab with Bevacizumab. This combination was first reported at the 2018 ASCO annual meeting in abstract form [15]. At that time, 26 patients were treated. The response rate was $62 \%$. Pishvaian et al updated the results at 2018 ESMO. As of 7/26/2018, 103 patients have been treated with the combination. The investigator-assessed response rate was $32 \%$. The overall disease control rate was $77 \%$. The duration of response was more than 6 months in $52 \%$ responders and more than 12 months in $26 \%$ responders. These are impressive results that warrant further evaluation in a large, randomized phase III setting. Another combination of Lenvatinib plus Pembrolizumab was investigated in phase I study that was reported at 2018 ASCO annual meeting as well [16]. There were a total of 18 patients enrolled in the study. All patients experienced tumor reduction except for one patient who was not evaluable. Currently, a phase III study comparing combination therapy to lenvatinib alone is on the way. Additionally, lenvatinib in combination with nivolumab is currently being evaluated in Asia (Table 2).

\section{Conclusions}

Systemic therapy for advanced hepatocellular carcinoma is evolving rapidly, and therapy should be tailored to the individual patient. For those with symptoms caused by cancer such as pain from a large tumor stretching the hepatic capsule, for whom a quick reduction of the tumor size is needed to palliate symptoms, Lenvatinib might be a good option as it produces higher response rates than Sorafenib. For those with autoimmune disease, anti-PD-1 antibodies should be used with caution. For those who experience disease recurrence after liver transplant, both Nivolumab and Pembrolizumab

Table 1. Randomized phase III trials in advanced hepatocellular carcinoma

\begin{tabular}{|c|c|c|c|c|}
\hline Trial name & $\begin{array}{c}\text { Number of } \\
\text { patients }\end{array}$ & Response rate & Median overall survival & Progression free survival \\
\hline $\begin{array}{l}\text { SHARP } \\
\text { Sorafenib vs. placebo }\end{array}$ & 602 & $\begin{array}{c}7 \% \text { PR and } 71 \% \text { SD sorafenib vs. } \\
1 \% \mathrm{PR} \text { and } 67 \% \text { SD placebo }\end{array}$ & $\begin{array}{l}10.7 \text { mos sorafenib vs. } 7.9 \mathrm{mos} \\
\text { placebo }\end{array}$ & 5.5 mos sorafenib vs. 2.8 mos placebo \\
\hline $\begin{array}{l}\text { Cheng et al. } \\
\text { Sorafenib vs. Placebo }\end{array}$ & 271 & $\begin{array}{l}3.3 \% \text { PR and } 54 \% \text { SD sorafenib vs. } \\
1.3 \% \text { PR and } 27.6 \% \text { SD placebo }\end{array}$ & $\begin{array}{l}6.5 \text { mos sorafenib vs. } 4.2 \mathrm{mos} \\
\text { placebo }\end{array}$ & 2.8 mos sorafenib vs. 1.4 mos placebo \\
\hline $\begin{array}{l}\text { BRISK-PS } \\
\text { Brivanib vs. Placebo after progression } \\
\text { on Sorafenib }\end{array}$ & 395 & $10 \%$ Brivanib vs. $2 \%$ placebo & $\begin{array}{c}9.4 \text { mos Brivanib vs. } 8.2 \mathrm{mos} \\
\text { placebo }\end{array}$ & 4.2 mos Brivanib vs. 2.7 mos placebo \\
\hline $\begin{array}{l}\text { Cheng } \text { et al. } \\
\text { Sunitinib vs. Sorafenib }\end{array}$ & 1074 & $50.8 \%$ Sunitinib vs. $51.5 \%$ Sorafenib & $\begin{array}{l}7.9 \text { mos Sunitinib vs. } 10.4 \mathrm{mos} \\
\text { Sorafenib }\end{array}$ & 3.6 mos Sunitinib vs. 3 mos Sorafenib \\
\hline $\begin{array}{l}\text { Cainap et al. } \\
\text { Linifanib vs. Sorafenib }\end{array}$ & 1035 & $10 \%$ Linifanib vs. $6.1 \%$ Sorafenib & $\begin{array}{l}9.1 \text { mos Linifanib vs. } 9.8 \text { mos } \\
\text { Sorafenib }\end{array}$ & 4.2 mos Linifanib vs. $2.9 \mathrm{mos}$ Sorafenib \\
\hline $\begin{array}{l}\text { SEARCH } \\
\text { Sorafenib+Erlotinib vs. } \\
\text { Sorafenib+Placebo }\end{array}$ & 720 & $\begin{array}{l}\text { 6.6\% Sorafenib+erlotinib vs. } 3.9 \% \\
\text { Sorafenib+placebo }\end{array}$ & $\begin{array}{c}9.5 \text { mos Sorafenib+erlotinib vs. } 8.5 \\
\text { mos Sorafenib+placebo }\end{array}$ & $\begin{array}{c}3.2 \mathrm{mos} \text { Sorafenib+erlotinib vs. } 4 \mathrm{mos} \\
\text { Sorafenib+placebo }\end{array}$ \\
\hline $\begin{array}{l}\text { SARAH } \\
\text { Yttrium-90 (SIRT) vs. Sorafenib }\end{array}$ & 467 & $\begin{array}{c}19 \% \text { SIRT vs. } 12 \% \text { Sorafenib had CR } \\
\text { or PR }\end{array}$ & 8 mos SIRT vs. 9.9 mos Sorafenib & 4.1 mos SIRT vs. 3.7 mos Sorafenib \\
\hline $\begin{array}{l}\text { Kudo et al. } \\
\text { Lenvatinib vs. Sorafenib first line }\end{array}$ & 1492 & $24.1 \%$ Lenvatinib vs. $9.2 \%$ Sorafenib & $\begin{array}{l}13.6 \text { mos Lenvatinib vs. } 12.3 \\
\text { Sorafenib }\end{array}$ & $\begin{array}{l}7.4 \text { mos Lenvatinib vs. } 3.7 \mathrm{mos} \\
\text { Sorafenib }\end{array}$ \\
\hline
\end{tabular}

Table 2. Immune checkpoint trials in advanced hepatocellular carcinoma

\begin{tabular}{|l|c|c|c|}
\hline Trial name & Number of patients & Response rate & Median overall survival \\
\hline $\begin{array}{l}\text { CHECKMATE-040 } \\
\text { Phase I/II } \\
\text { Nivolumab dose escalation and expansion trial }\end{array}$ & 262 & $20 \%$ with $3 \mathrm{mg} / \mathrm{kg}$ & Not yet reached \\
\hline $\begin{array}{l}\text { KEYNOTE-224 } \\
\text { Phase II } \\
\text { Pembrolizumab in those pre-treated with Sorafenib }\end{array}$ & 104 & $17 \%$ & $54 \%$ \\
\hline $\begin{array}{l}\text { KEYNOTE-240 } \\
\text { Phase III } \\
\text { Pembrolizumab vs. Best Supportive Care Second Line }\end{array}$ & 408 & Ongoing & Ongoing \\
\hline $\begin{array}{l}\text { Pishvaian } \text { et al. } \\
\text { Atezolizumab+Bevacizumab phase IB }\end{array}$ & 103 & Ongoing & Ongoing \\
\hline $\begin{array}{l}\text { Ikeda et al } \\
\text { Phase I } \\
\text { Pembrolizumab+Lenvatinib }\end{array}$ & Ongoing & Ongoing & Ongoing \\
\hline $\begin{array}{l}\text { Phase Ib } \\
\text { Nivolumab+Lenvatinib }\end{array}$ & Ongoing & Ongoing \\
\hline
\end{tabular}


are contraindicated, as fatal graft rejection has been reported in the literature in this population. Immune checkpoint inhibitors have opened a new chapter in hepatocellular carcinoma therapy. However, the lack of available biomarkers is a major hurdle in effective patient selection. Although small gains have been made in this arena, such as microsatellite instability and tumor mutation burden testing, which are predictors for possible benefit from these agents, more research needs to be done to fill the gap.

\section{References}

1. Petrick JL, Kelly SP, Altekruse SF, McGlynn KA, Rosenberg PS, et al. (2016) Future of hepatocellular carcinoma incidence in the United States forecast through 2030. J Clin Oncol 34: 1787-1794. [Crossref]

2. 2019 Cancer facts and stats from American cancer society. 2019.

3. Llovet JM, Ricci S, Mazzaferro V, Hilgard P, Gane E, et al. (2008) Sorafenib in advanced hepatocellular carcinoma. $N$ Engl J Med 359: 378-390. [Crossref]

4. Cheng AL, Kang YK, Chen Z, Tsao CJ, Qin S, et al. (2009) Efficacy and safety of sorafenib in patients in the Asia-Pacific region with advanced hepatocellular carcinoma: A phase III randomised, double-blind, placebo-controlled trial. Lancet Oncol 10: 25-34. [Crossref]

5. Finn RS, Kang YK, Mulcahy M, Polite BN, Lim HY, et al. (2012) Phase II, openlabel study of brivanib as second-line therapy in patients with advanced hepatocellular carcinoma. Clin Cancer Res 18: 2090-2098. [Crossref]

6. Park JW, Finn RS, Kim JS, Karwal M, Li RK, et al. (2011) Phase II, open-label study of brivanib as first-line therapy in patients with advanced hepatocellular carcinoma. Clin Cancer Res 17: 1973-1983. [Crossref]

7. Johnson PJ, Qin S, Park JW, Poon RT, Raoul JL, et al. (2013) Brivanib versus sorafenib as first-line therapy in patients with unresectable, advanced hepatocellular carcinoma: results from the randomized phase III BRISK-FL study. J Clin Oncol 31: 3517-3524. [Crossref]
8. Llovet JM, Decaens T, Raoul JL, Boucher E, Kudo M, et al. (2013) Brivanib in patients with advanced hepatocellular carcinoma who were intolerant to sorafenib or for whom sorafenib failed: results from the randomized phase III BRISK-PS study. J Clin Oncol 31: 3509-3516. [Crossref]

9. Cheng AL, Kang YK, Lin DY, Park JW, Kudo M, et al. (2013) Sunitinib versus sorafenib in advanced hepatocellular cancer: Results of a randomized phase III trial. $J$ Clin Oncol 31: 4067-4075. [Crossref]

10. Toh HC, Chen PJ, Carr BI, Knox JJ, Gill S, et al. (2013) Phase 2 trial of linifanib (ABT$869)$ in patients with unresectable or metastatic hepatocellular carcinoma. Cancer 119: 380-387. [Crossref]

11. Zhu AX, Rosmorduc O, Evans TR, Ross PJ, Santoro A, et al. (2015) SEARCH: A phase III, randomized, double-blind, placebo-controlled trial of sorafenib plus erlotinib in patients with advanced hepatocellular carcinoma. J Clin Oncol 33: 559-566.

12. Kudo M, Finn RS, Qin S, Han KH, Ikeda K, et al. (2018) Lenvatinib versus sorafenib in first-line treatment of patients with unresectable hepatocellular carcinoma: A randomised phase 3 non-inferiority trial. Lancet 391: 1163-1173.

13. El-Khoueiry AB, Sangro B, Yau T, Crocenzi TS, Kudo M, et al. (2017) Nivolumab in patients with advanced hepatocellular carcinoma (CheckMate 040): An open-label, non-comparative, phase 1/2 dose escalation and expansion trial. Lancet 389: 24922502. [Crossref]

14. Zhu AX, Finn RS, Edeline J, Cattan S, Ogasawara S, et al. (2018) Pembrolizumab in patients with advanced hepatocellular carcinoma previously treated with sorafenib (KEYNOTE-224): a non-randomised, open-label phase 2 trial. Lancet Oncol 19: 940952. [Crossref]

15. Stein S, Pishvaian MJ, Lee MS, Lee KH, Hernandez S, et al. (2018) Safety and clinical activity of $1 \mathrm{~L}$ atezolizumab+bevacizumab in a phase $\mathrm{Ib}$ study in hepatocellular carcinoma (HCC). J Clin Oncol 36.

16. Ikeda M, Sung MX, Kudo M, Kobayashi M, Baron AD, et al. (2018) A Phase Ib trial of lenvatinib (Len) plus pembrolizumab (PEM) in patients with unresetable hepatocelluar carcinoma (HCC). J Clin Oncol.

Copyright: (C2019 Elder S. This is an open-access article distributed under the terms of the Creative Commons Attribution License, which permits unrestricted use, distribution, and reproduction in any medium, provided the original author and source are credited. 